\title{
Evaluation of drops dimensions in time and rheological properties of the multiple emulsion
}

\author{
Marta Major-Godlewska ${ }^{1}$
}

Received: 6 February 2019 / Accepted: 20 March 2019 / Published online: 4 April 2019

(c) The Author(s) 2019

\begin{abstract}
Results of drops dimension and rheological properties of the produced multiple emulsion are presented in this paper. Sunflower oil (oil phase), distilled water (liquid phase), and lecithin from soya beans were used as materials to produce emulsion. Emulsions were produced in vessel with inner diameter $D=0.1 \mathrm{~m}$ and liquid height $H=0.5 D$. Smith turbine has been used to stir the emulsions. Examination of the drops dimension and rheological properties were conducted for emulsions collected after $15 \mathrm{~min}$ and $45 \mathrm{~min}$ of stirring as well as after the 3rd and 30th day. There were 6 measurements altogether. To do the analysis of drops dimension, in each series 700-800 inner oil-phase drops were taken. The results were presented in a form of graphics as a distribution of drops. The dimensions of the drops obtained $d$ were also presented as a minimal diameter $d_{\min }$, arithmetic mean diameter $d_{\mathrm{a}}$, median $d_{\mathrm{m}}$, and Sauter mean diameter $d_{32}$. The results of the research of rheological emulsions were presented graphically as a viscosity curve and they were described by Herschel-Bulkley model (Eq. 4)
\end{abstract}

Keywords Multiple emulsion $\cdot$ Microscopic analysis $\cdot$ Rheological measurements

\section{List of symbols}

$B \quad$ Width of the baffles (m)

$D \quad$ Inner diameter of the vessel (m)

$d_{\mathrm{s}} \quad$ Diameter of the stirrer $(\mathrm{m})$

$d \quad$ Diameter of the drop $(\mu \mathrm{m})$

$d_{\mathrm{a}} \quad$ Arithmetic mean diameter of the drop $(\mu \mathrm{m})$

$d_{\mathrm{m}} \quad$ Mediana diameter of the drop $(\mu \mathrm{m})$

$d_{32}$ SAUTER mean diameter $(\mu \mathrm{m})$

$d_{43} \quad$ Volume-weighted mean diameter $(\mu \mathrm{m})$

$H \quad$ Liquid height in the vessel (m)

$J \quad$ Number of baffles

$n \quad$ Stirrer speed

$Z \quad$ Number of stirrer blades $\left(\mathrm{s}^{-1}\right)$

\section{Greek letters}

$\tau \quad$ Shear stress $(\mathrm{Pa})$

$\gamma \quad$ Shear rate $\left(\mathrm{s}^{-1}\right)$

\section{Introduction}

Double emulsions are systems, where the inner phase contains outer-phase droplets. That is why it is possible to distinguish two types of double emulsions: emulsion water in oil in water $(\mathrm{W} / \mathrm{O} / \mathrm{W})$ and emulsion oil in water in oil $(\mathrm{O} / \mathrm{W} / \mathrm{O})$. In emulsions $\mathrm{W} / \mathrm{O} / \mathrm{W}$ the water phase is additionally dispersed in oil phase, whereas in $\mathrm{O} / \mathrm{W} / \mathrm{O}$ emulsions the oil phase is additionally dispersed in water phase. In both cases, the interim phase creates a peculiar kind of membrane between two identical phases. Another kind of double emulsions is the one in which two different water phases marked as $\mathrm{W}_{1} / \mathrm{O} / \mathrm{W}_{2}$ or two different oil phases $\left(\mathrm{O}_{1} / \mathrm{W} / \mathrm{O}_{2}\right)$ were applied. It is necessary to remember, that liquids used during emulsions creation cannot dissolve in themselves.

The dimension of the multiple emulsion drop is presented as a distribution of drops dimension by Mehrania et al. (2017), Yamanaka et al. (2017), Matos et al. (2014), Andrade and Corredig (2016). The description of drops dimension is also presented for example by Sajjadi et al. (2003), Bou et al. (2014), Matos et al. (2014), Andrade and Corredig (2016), Mohammadi et al. (2016) as volume-surface (Sauter) mean diameters $d_{32}$ were determined using the following relation presented,

Marta Major-Godlew
mmajor@zut.edu.pl

1 Faculty of Chemical Technology and Engineering, West Pomeranian University of Technology, al. Piastów 42, 71-605 Szczecin, Poland 


$$
d_{32}=\frac{\sum_{i=0}^{i \max } x_{i} d_{i}^{3}}{\sum_{i=0}^{i \max } x_{i} d_{i}^{2}},
$$

where $x_{\mathrm{i}}$-number of particles.

Matos et al. (2014), Mohammadi et al. (2016) also present the characteristics of emulsion drops as volume-weighted (De-Brouker) mean diameter $\mathrm{d}_{43}$,

$$
d_{43}=\frac{\sum_{i=0}^{i \max } x_{i} d_{i}^{4}}{\sum_{i=0}^{i \max } x_{i} d_{i}^{3}} .
$$

Perez-Moral et al. (2014), Schuch et al. (2013, 2014) and Ursica et al. (2005) papers also present W/O/W type of emulsion. Perez-Moral et al. (2014) investigated the role of different emulsifiers and a simple novel approach to gel the internal aqueous droplets to improve the stability to heat, shear, and the presence of salt. In their study polyglycerol polyricinoleate (PGPR 4125) was used as emulsifier. Another emulsifier was used in their study than lecithin. Lecithin was found to be the most stable emulsifier to heating. The main objective of the work Schuch et al. (2013) was to investigate a structural parameter, namely the dispersed phase content of the inner emulsion, on breakup of doubleemulsion droplets. The inner emulsions were rheologically characterised to explain the breakup behaviour. They think that breakup of double-emulsion drops was comparable to breakup of simple-emulsion droplets. According to them the breakup behaviour can be described and predicted by the viscosity ratio (viscosity inner and outer emulsion). The comparison of different emulsification devices for the production of $\mathrm{W} / \mathrm{O} / \mathrm{W}$ double emulsion was presented by Schuch et al. (2014). Ursica et al. (2005) presented the analysis of drops dimensions for seven multiple emulsions $\mathrm{W} / \mathrm{O} / \mathrm{W}$ as distribution histogram. The particle size analysis was accomplished by the microscopic images of the samples. In their paper, the evaluation of the median diameter in time for seven different multiple emulsion was presented.

The topic connected with emulsions $\mathrm{W} / \mathrm{O} / \mathrm{W}$ was extensively presented by Hino et al. (2000), Okochi and Nakano (2000), and Jimenez-Colmenero (2013). Hino el al. (2000) presented stabilisation of $\mathrm{W} / \mathrm{O} / \mathrm{W}$ emulsion and its application to transcatheter arterial embolization therapy. The preparation and application of $\mathrm{W} / \mathrm{O} / \mathrm{W}$ type emulsions entrapping vancomycin were presented by Okochi and Nakano (2000). Jimenez-Colmenero (2013), in the article offers a detailed review of the specific possibilities and food applications of multiple emulsions for the development of healthier food, including functional foods.

The research with double emulsions, where the oil phrase is additionally dispersed in water phrase $(\mathrm{O} / \mathrm{W} / \mathrm{O})$, were also of Pal (1996) and Dłuska and Markowska-Radomska (2010) interest. Pal (1996) presented the rheological behaviour of simple oil in water in oil emulsions. Dłuska and MarkowskaRadomska (2010) described the effect of operating parameters in the Couette-Taylor flow (CTF) contactor on multiple emulsion appearance, drop size, packing, and rheological behaviour.

Wide usage of emulsions in different industry branches contributes to conducting research on multiple emulsions formation, their stability and defining their structure and determining their properties. To create emulsion, it is necessary to lower the phase-to-phase tension on the border of phases. That effect is ensured thanks to a presence of the appropriate surfactant. In cosmetic or pharmaceutic emulsions it seems to be good to use lecithin as an emulsifier. Lecithin belongs to a group of natural, amphoteric emulsifiers. It is obtained from such plants as soya, sunflower, and rape (Molski 2009; Brud and Glinka, 2001).

The aim of the paper was to define structure changes, including drops dimensions during multiple emulsion production using soya lecithin in the vessel equipped with standard planar baffles and Smith's turbine. The character and dimension of emulsion drops, which were put aside for 3 days and then mixed by shaking or Smith turbine mechanical mixing, were specified. The process of drops dimension measurement was repeated after 30 days. In this paper the rheological properties of the emulsion produced and the emulsion in the 30 days of its production were specified.

\section{Experimental}

\section{Materials}

In the studies sunflower oil (refined sunflower oil produced for Jeronimo Martins Polska S.A.) was used as oil phase and distilled water as water phase. Lecithin from soya beans (producer: Vemica) was used as an emulsifier. Sudan III (producer: EUROCHEM BGD Sp. z o.o.) was used to the colour oil phase.

\section{Experimental set up}

The emulsions were produced in a vessel with transparent wall made of organic glass, with inner diameter $D=0.1 \mathrm{~m}$ (Fig. 1). The vessel was filled with liquid up to the height $H=0.5 D$. Four $(J=4)$ planar baffles of width $B=0.1 D$ were mounted in the vessel with the flat bottom. The Smith 


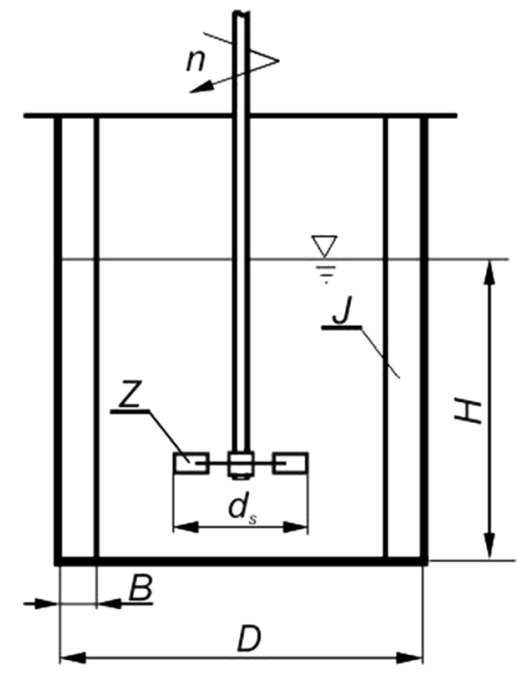

Fig. 1 Geometrical parameters of the vessel

turbine (CD 6) of diameter $d_{s}=0.33 D$ and number of stirrer blades $Z=6$ was used in the measurements.

\section{Procedure of the emulsion production}

The part of individual phase contained $70 \mathrm{vol} \%$ of oil phase and 30 vol.\% of water phase. In distilled water phase $8 \mathrm{~g}$ soya lecithin was solved (it corresponds to 6.4 mass \% of lecithin related to water phase) and stirred with magnetic agitator until mixture homogeneity was obtained. Such prepared water phase was poured to the vessel with Smith's turbine. Sunflower oil, earlier coloured with Sudan III, was poured to the mixture of distilled water and soya lecithin. The emulsion was produced by stirring water phase and oil phase with Smith's turbine, rotation frequency $500 \mathrm{rpm}$. Samples to describe emulsion produced and determined drops dimension and rheological properties were collected after 15 and $45 \mathrm{~min}$ of stirring. After $45 \mathrm{~min}$ the produced emulsion was divided into two samples which were set aside for 3 and 30 days. The coalescence effect leading to stages stratification was observed. After 3 as well as after 30 days before conducting the research emulsions were stirred and shaken to obtain homogeneity.

\section{Rheological measurements and microscopic analysis}

Rheological measurements were performed using rheoviscometer type RT 10 by firm Haake with the system of two co-axial cylinders (DG 41). Measurements were conducted for the shear rate $<501 / \mathrm{s}$ and temperature $23^{\circ} \mathrm{C}$.

Microscopic analysis of the investigated samples was conducted to gain information about the multiple characteristics of the emulsion. Images were taken with diagnostic inverted microscope OPTA-TECH MW - 100, with software and digital camera OPTA-TECH 5MP.

\section{Results and discussion}

Samples to define emulsion produced were collected after 15 and 45 min stirring with Smith's turbine with the rotation frequency $500 \mathrm{rpm}$. The images of drops of multiple emulsion produced for the two given stirring times are presented in Fig. 2. The emergence of multiple emulsion oil in water in oil $(\mathrm{O} / \mathrm{W} / \mathrm{O})$, with irregular shapes of water phase, was observed.

On the basis of images taken, programme Opta View, rays and dimensions of inner oil-phase drops were defined. The population of inner oil-phase drops in the number from 700 to 800 was taken to the analysis. Sauter mean diameter $d_{32}$ was determined using the relation (1). The arithmetic mean diameter $d_{a}$ calculated as the sum of the droplets diameter divided by the number of droplets,

$d_{a}=\frac{\sum_{i=1}^{x} x_{i} d_{i}}{\sum_{i=1}^{x} x_{i}}$.
Fig. 2 Images of drops of multiple emulsion produced $\mathrm{O} / \mathrm{W} / \mathrm{O}$ for stirring times; a $15 \mathrm{~min}, \mathbf{b}$ 45 min (enlargement $4 \times$ )

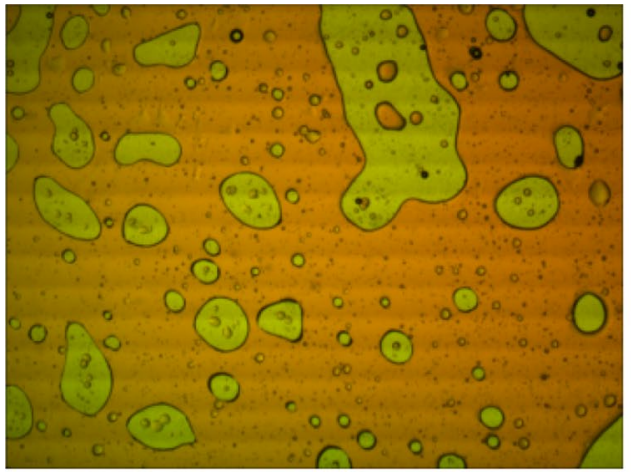

(a)

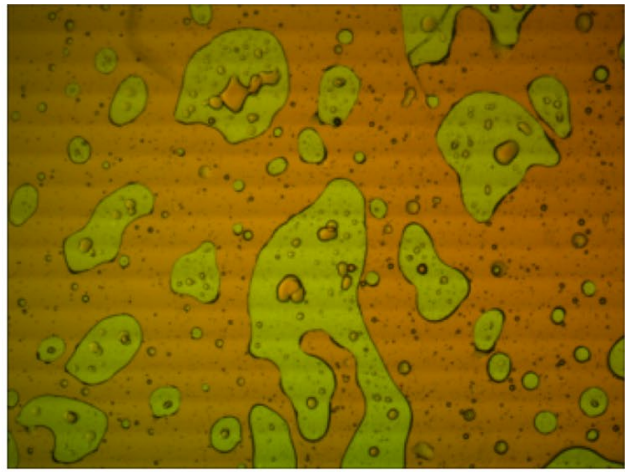

(b) 


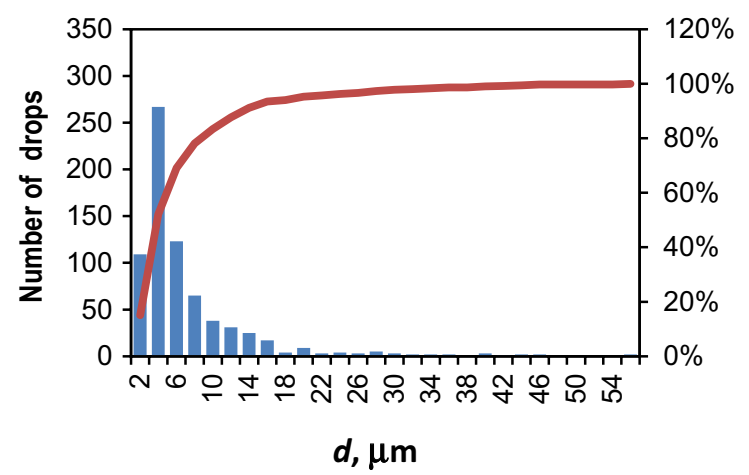

(a)

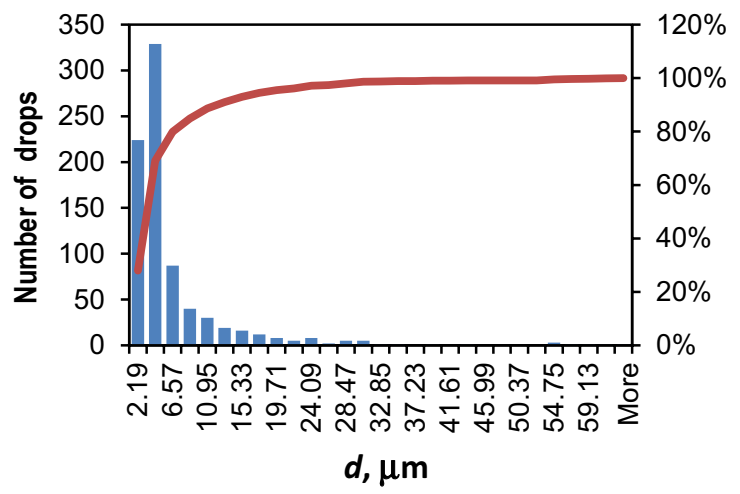

(b)

Fig. 3 Distribution of inner oil-phase drops of O/W/O emulsion; a for $15 \mathrm{~min}$; b for $45 \mathrm{~min}$;

intensity (-) summary volume \%

Distribution of inner oil-phase drops in the produced oil in water in oil emulsion, for the sample stirred for $15 \mathrm{~min}$ was presented in histogram in the Fig. 3a, and for the time of 45 min in Fig. $3 b$.

Analysing data presented in Fig. 3a, b it was possible to observe, that the biggest collection of inner oil-phase drops being $37 \%$ of the whole population in question, is in the range of diameters from 2 to $4 \mu \mathrm{m}$, for the sample collected after $15 \mathrm{~min}$ of stirring (Fig. 3a) and in the range of 2.19-4.38 $\mu \mathrm{m}$ for the sample stirred for $45 \mathrm{~min}$ (Fig. 3b), where the number of drops appearance equals $41 \%$ of the whole inner oil-phase drops tested. The $13 \%$ bigger appearance of inner oil-phase drops number of diameter smaller than $2.19 \mu \mathrm{m}$ was visible too, when the emulsion was stirred for $45 \mathrm{~min}$ in comparison to the emulsion stirred for $15 \mathrm{~min}$ It leads to the conclusion that the prolonging stirring time influences the occurrence of the bigger number of smallerdiameter inner oil phase drops.

Putting the emulsion aside caused gradual, slow phases stratification. The drops dimension measurement were again conducted after 3 days from the moment of $\mathrm{O} / \mathrm{W} / \mathrm{O}$ emulsion production. One sample of emulsion was stirred before the measurements, with Smith's turbine with the rotation frequency $500 \mathrm{rpm}$ about $1 \mathrm{~min}$. The second sample was shaken manually until homogeneity was obtained about $1 \mathrm{~min}$, too. Obtaining homogeneity of the samples again caused oil in water in oil emulsion (O/W/O, Fig. 4) production.

In both cases of the drops population in question, the biggest number of drops was observed (Fig. 5a) for diameters of inner oil-phase drops smaller than $d=5 \mu \mathrm{m}$ with emulsion, which after 3 days of before the measurements, to gain homogeneity, was stirred again with Smith's turbine and for $d<3.86 \mu \mathrm{m}$ (Fig. 5b) for the sample, which was shaken to gain homogeneity. Values of the mean arithmetic diameter inner oil phase emulsion drops equal, respectively, $d_{a}=8.30 \mu \mathrm{m}$ for mechanically stirred sample and $d_{\mathrm{a}}=5.84 \mu \mathrm{m}$ for the sample shaken before the drops dimension measurement.

Observation of the number of drops of inner oil phase was also conducted after 30 days from the moment of emulsion production. Similarly to 3 as well as 30 days emulsion underwent stratification, that is why, before the measurements, to homogenise the sample, one sample was stirred mechanically for about $1 \mathrm{~min}$ and the second one was shaken manually for about $1 \mathrm{~min}$ The images of the samples obtained
Fig. 4 Images of multiple emulsion drops $\mathrm{O} / \mathrm{W} / \mathrm{O}$ after 3 days from the moment of production (enlargement $4 \times$ ); a stirred sample, b shaken sample

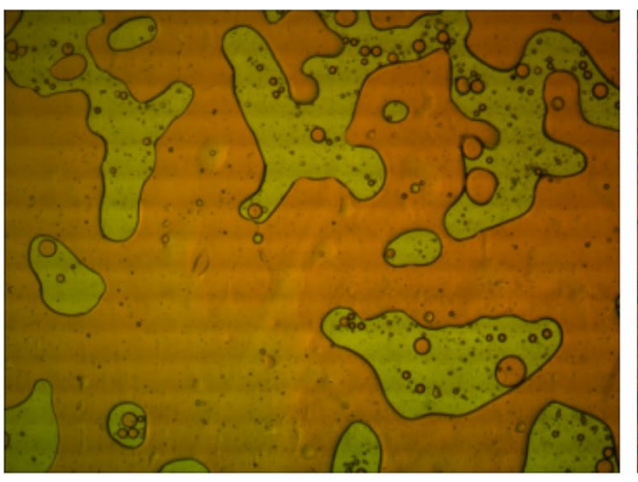

(a)

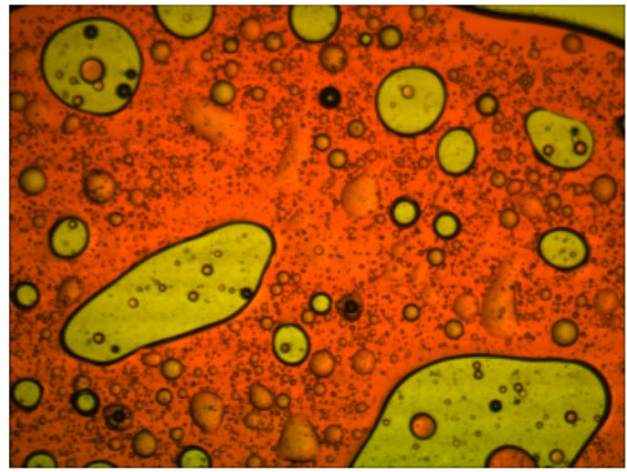

(b) 


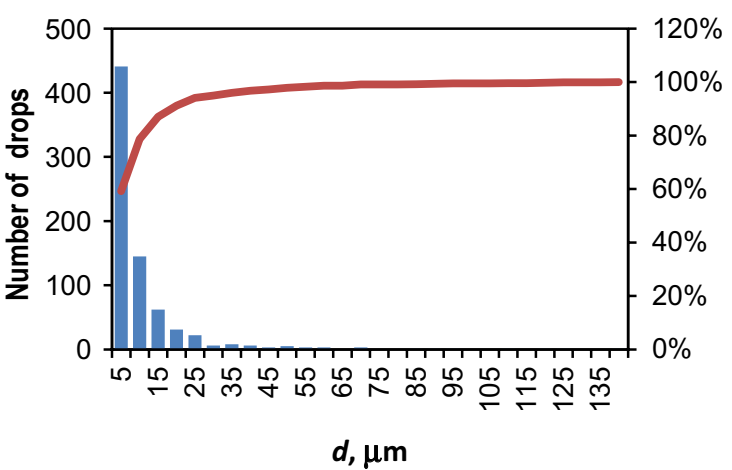

(a)

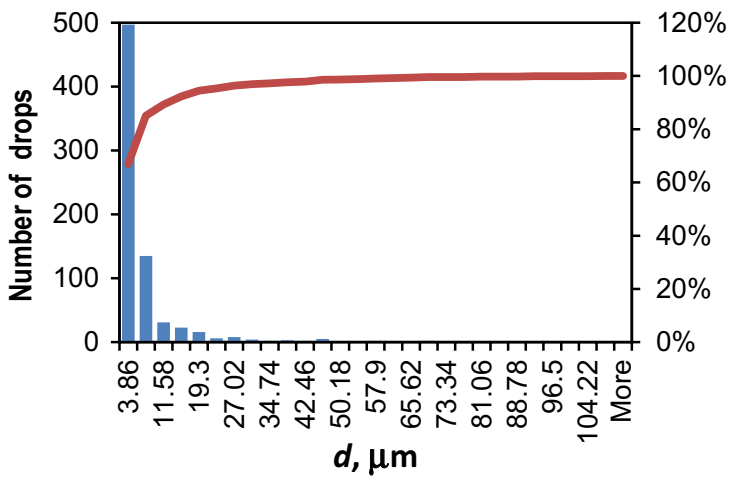

(b)

Fig. 5 Distribution of inner oil-phase drops emulsion O/W/O obtained after 3 days of emulsion production; volume \%; a stirred sample, b shaken sample

Fig. 6 Images of multiple emulsion drops $\mathrm{O} / \mathrm{W} / \mathrm{O}$ after 30 days from the moment of production (enlargement $4 \times$ ); a stirred sample, b shaken sample

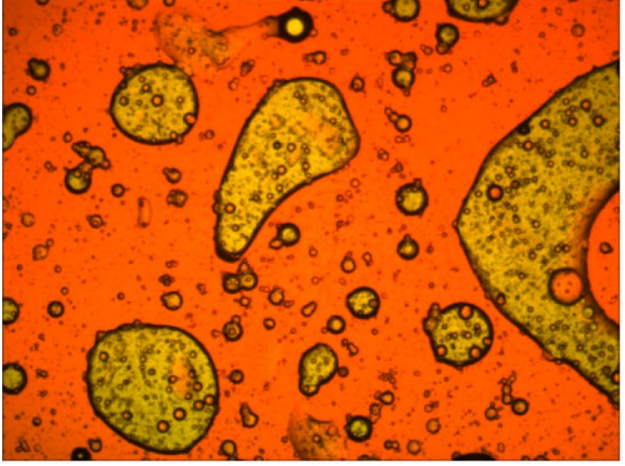

(a)

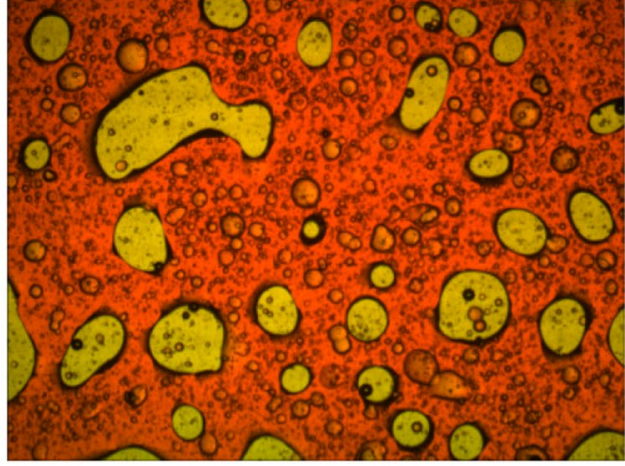

(b)

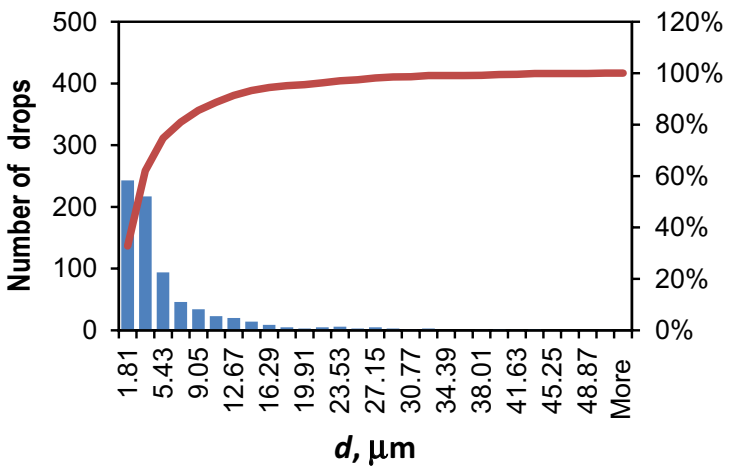

(a)

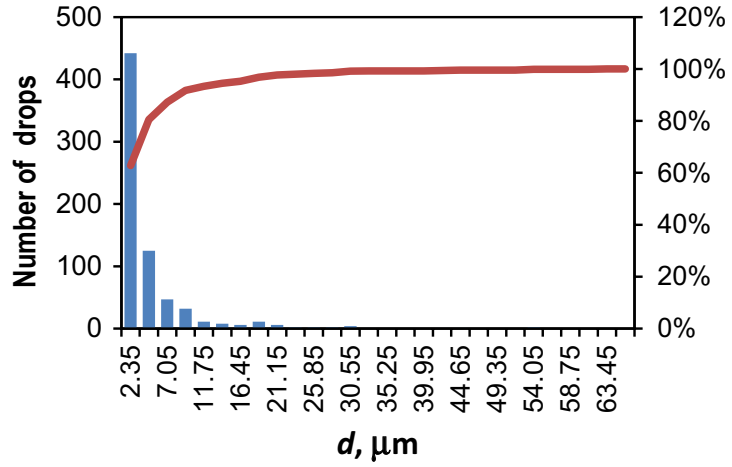

(b)

Fig. 7 Distribution of inner oil phase emulsion O/W/O drops after 30 days; shaken sample;

after 30 days from the stirred or shaken sample production are presented in Fig. 6. The analysis of diameter values of the inner oil-phase drops presented in a form of histogram in Fig. 7a indicates the presence of $33 \%$ of the whole population of drops of diameter $d<1.81 \mu \mathrm{m}$ and about $29 \%$ of drops of diameters of the range between 1.82 and $3.62 \mu \mathrm{m}$. It means that more than a half of population in question is of $d<3.62 \mu \mathrm{m}$ dimension.

A different distribution of drops is visible in values of data analysed of inner oil phase of the produced emulsion 
Table 1 The sizes and values of population of inner oil-phase drops of the emulsion produced
Fig. 8 Comparison of inner oil-phase drops distribution of emulsion $\mathrm{O} / \mathrm{W} / \mathrm{O}$ for the alternative drop diameter $d 20 \mu \mathrm{m}$; (filled square) 15 min (open diamond) 45 min (open triangle) 30 days stirred (open circle) 30 days shaken

\begin{tabular}{lllllll}
\hline Time & 15 min & 45 min & 3 day stirred & 3 day shaken & 30 day stirred & 30 day shaken \\
\hline$d_{\min }(\mu \mathrm{m})$ & 0.78 & 0.74 & 0.78 & 0.78 & 0.62 & 0.76 \\
$d_{\mathrm{a}}(\mu \mathrm{m})$ & 6.37 & 5.49 & 8.30 & 5.84 & 5.06 & 3.95 \\
$d_{\mathrm{m}}(\mu \mathrm{m})$ & 3.88 & 2.96 & 3.88 & 2.62 & 2.58 & 1.78 \\
$d_{32}(\mu \mathrm{m})$ & 26.11 & 32.37 & 68.86 & 52.64 & 23.69 & 29.52 \\
Number & 722 & 801 & 745 & 743 & 741 & 704 \\
\hline
\end{tabular}

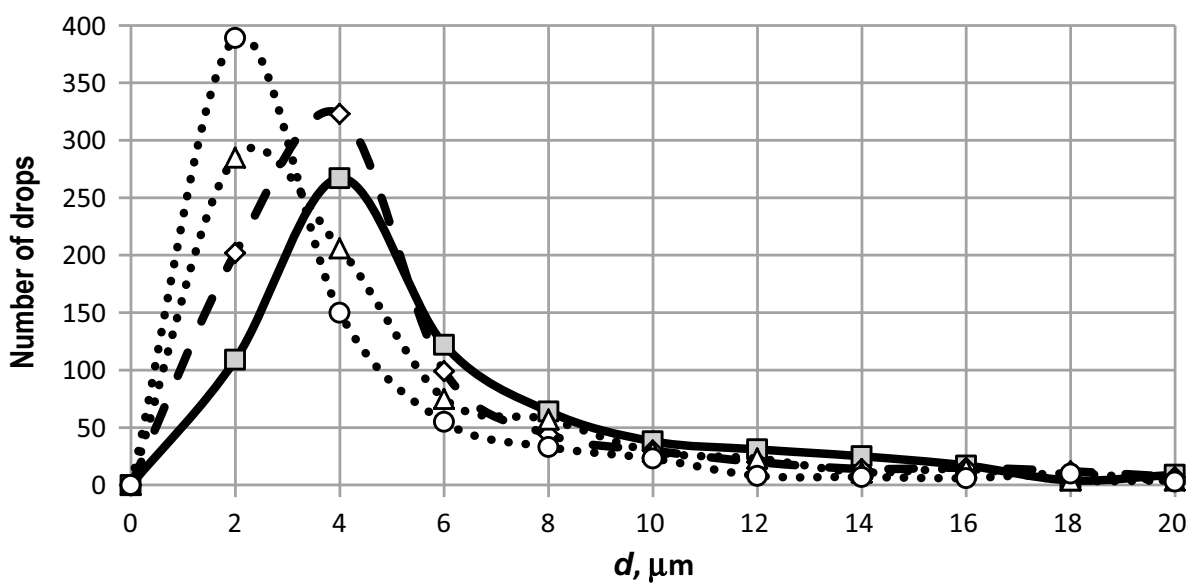

diameters obtained, which after 30 days was re-shaken to gain homogeneity (Fig. 7b). The existence of significant, $63 \%$ population of drops analysed was spotted, drops of the $d<2.35 \mu \mathrm{m}$ diameter. The number of drops of diameters belonging to another range $2.36 \mu \mathrm{m}<d<4.7 \mu \mathrm{m}$ was only $18 \%$ of the analysed population. Thanks to such drops distribution, the value of mean alternative drops diameter was calculated and equals $d_{\mathrm{a}}=3.95 \mu \mathrm{m}$. This value is smaller than the value of mean drops diameter $d_{\mathrm{a}}=5.06 \mu \mathrm{m}$ for emulsion, which was re-stirred before the analysis.

Table 1 collectively presents the sizes and volumes of population of inner oil-phase drops of the emulsion produced, obtained on the basis of experimental data taken to the analysis. The size of drops was presented as a minimal diameter $d_{\mathrm{min}}$, arithmetic mean drops $d_{\mathrm{a}}$, median $d_{\mathrm{m}}$ and Sauter mean diameter $d_{32}$. The minimal value of drops diameter in the emulsion analysed in three cases was equal $d_{\min }=0.78 \mu \mathrm{m}$, and in the other three was a bit smaller. It was observed that prolonging the stirring time for $30 \mathrm{~min}$ does not cause appearance of much smaller minimal drops values. The mean value of the arithmetic diameter and median gets smaller with the time of stirring. Prolonging the stirring time also affects the size of Sauter mean diameter, which is $d_{32}=32.37 \mu \mathrm{m}$ in $45 \mathrm{~min}$ of stirring and is $6.26 \mu \mathrm{m}$ bigger than mean diameter obtained after $15 \mathrm{~min}$ of stirring. Analysing the values of diameters in so called emulsion 'ageing', it is proper to say that the biggest values of the mean arithmetic drop diameter $d_{\mathrm{a}}$ and the Sauter mean

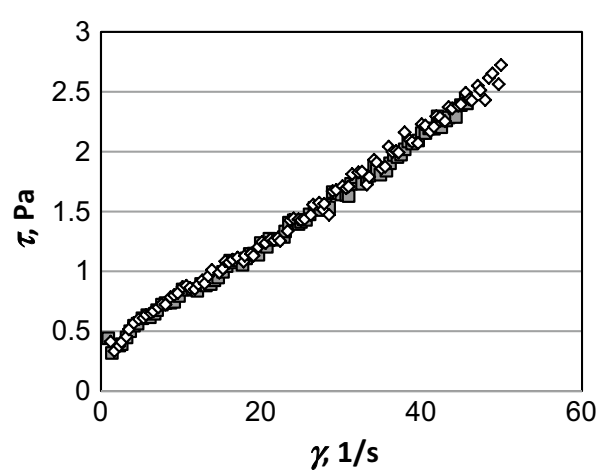

Fig. 9 Relation $=\mathrm{f}($ ) for the emulsion stirred for (filled square) 15 and (open diamond) $45 \mathrm{~min}$

diameter $d_{32}$ were obtained for the produced emulsion stirred with Smith's turbine after 3 days of its production.

Additionally collected set of drops was compared, with the assumption that $d 20 \mu \mathrm{m}$, which is mean $95 \%$ of the analysed population of inner oil phase drops. The same range of mean alternative drops diameter every $2 \mu \mathrm{m}$ was designated for this aim. Having compared the data presented in Fig. 8 it was possible to state that bigger number of smaller diameter drops was obtained after prolonging the stirring time to $45 \mathrm{~min}$. The time when the slow emulsion 'ageing' happens also has influence on the size of drops. Comparing the data obtained on the day of emulsion production after 45 min with the data obtained on the 30 day from emulsion production, the curve shift towards smaller values of inner oil phase diameter was observed. 
Fig. 10 Relation $=f()$ for the produced emulsion stirred for 45 min (open diamond) and for the 30 days (open triangle) (open circle); a stirred sample (open triangle), b shaken sample emulsion (open circle)

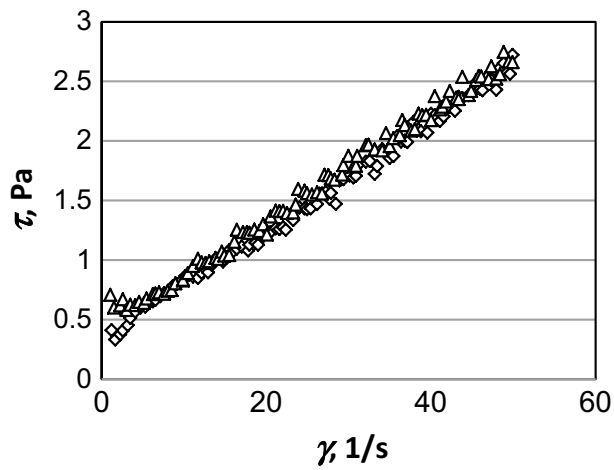

(a)

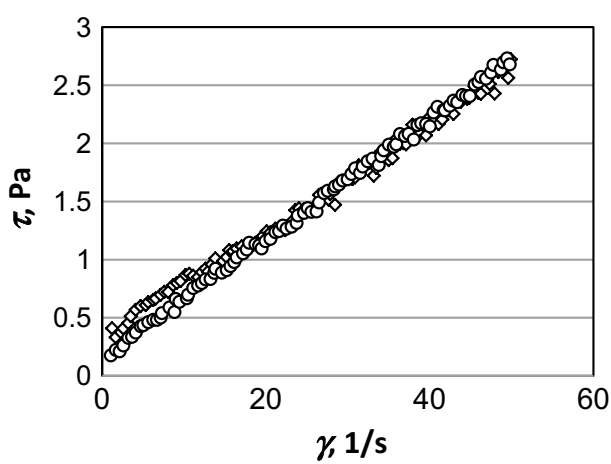

(b)
Rheological properties of the produced emulsion were presented as $=f()$ in Fig. 9. On the basis of the data obtained after analysis it is possible to state that prolonging the stirring time by $30 \mathrm{~min}$ did not significantly affect the change of curves. The emulsion flow curves produced after $15 \mathrm{~min}$ and $45 \mathrm{~min}$ of stirring were described by Herschel-Bulkley model.

$\tau=0.36+\left(0.0362 \times \gamma^{1.053}\right)$.

Herschel-Bulkley model presented by the Eq. (4) describes the experimental data with the mean error $3.5 \%$, for the shear speed range $1<, 1 / \mathrm{s}<50$.

In Fig. 10a the data presented in a form of equation $=f()$ of emulsion were compared, which during the production process was stirred with Smith's turbine for $45 \mathrm{~min}$ and emulsion, which after production was put aside for 30 days, and before the rheological measurements it was stirred mechanically. There were no significant changes stated in the strain-shearing values with the given strain speeds from the range $1<, 1 / \mathrm{s}<50$ in both compared emulsions. It is different (Fig. 10b) when the earlier produced emulsion is shaken after 30 days to obtain homogeneity. In such case differences in strain shearing values with strain speed $<151 /$ s. Smaller values of strain shearing were obtained for the emulsion, which was re-shaken after 30 days. Beyond $<20$ 1/s values for the data of both analysed emulsions are similar.

\section{Conclusions}

On the basis of research and data obtained during emulsion production in the vessel of the $D=0.1 \mathrm{~m}$ and $H=0.5 D$, with Smith's turbine $\left(d_{s}=0.33 D\right)$, it stated that multiple emulsion oil in water in oil $(\mathrm{O} / \mathrm{W} / \mathrm{O})$ was produced. It was possible for $\mathrm{O} / \mathrm{W} / \mathrm{O}$ emulsion consisting of $70 \mathrm{vol} \%$ sunflower oil and $30 \mathrm{vol} \%$ distilled water in which $8 \mathrm{~g}$ soya lecithin (it corresponds to 6.4 mass.\% of lecithin related to water phase) was solved. Such emulsion was produced in 15 and $45 \mathrm{~min}$ of stirring, with the rotation frequency equal to $500 \mathrm{rpm}$. The emulsion produced is not stable and stratifies in time. However, mechanical re-stirring or re-shaking causes the return to the previously described type of emulsion $\mathrm{O} / \mathrm{W} / \mathrm{O}$.

Prolonging the stirring time with Smith's turbine affects the change of mean alternative drop diameter, decreasing its value (for $15 \min d=6.37 \mu \mathrm{m}$, and for $45 \min d=5.49 \mu \mathrm{m}$ ). In case of mean Sauter diameter its value increases with time of stirring used at work $\left(d_{32}=26.11 \mu \mathrm{m}\right.$ for 15 min stirring, $d_{32}=32.37 \mu \mathrm{m}$ for $45 \mathrm{~min}$ stirring).

The results received after 3 and 30 days show that, according to size distribution analyses it is obvious that re-shaking of emulsion leads to better dispersion than re-stirring.

The rheological properties of the emulsion produced during 15 and 45 min of stirring were described by Herschel-Bulkley model presented by the Eq. (4) appropriate for the range of strain speed $1<, 1 / \mathrm{s}<50$.

The rheological properties of emulsion practically do not change when the emulsion is re-stirred or re-shaked manually after 30 days.

Open Access This article is distributed under the terms of the Creative Commons Attribution 4.0 International License (http://creativeco mmons.org/licenses/by/4.0/), which permits unrestricted use, distribution, and reproduction in any medium, provided you give appropriate credit to the original author(s) and the source, provide a link to the Creative Commons license, and indicate if changes were made.

\section{References}

Andrade J, Corredig M (2016) Vitamin D3 and phytosterols affect the properties of polyglycerol polyricinoleate (PGPR) and protein interface. Food Hydrocoll 54:278-283. https://doi.org/10.1016/j. foodhyd.2015.10.001

Bou R, Cofrades S, Jimenez-Colmenero FJ (2014) Physicochemical properties and riboflavin encapsulation in double emulsions with different lipid sources. LWT Food Sci Technol 59:621-628. https ://doi.org/10.1016/j.1wt.2014.06.044

Brud WS, Glinka R (2001) Cosmetics technology. Oficyna Wydawnicza MA, Łódź (in Polish) 
Dłuska E, Markowska-Radomska A (2010) Regimes of multiple emulsions of $\mathrm{W}_{1} / \mathrm{O} / \mathrm{W}_{2}$ and $\mathrm{O}_{1} / \mathrm{W} / \mathrm{O}_{2}$ type in the continuous CouetteTaylor flow contactor. Chem Eng Technol 1:113-120. https://doi. org/10.1002/ceat.200900278

Hino T, Kawashima Y, Shimabayashi S (2000) Basic study for stabilization of w/o/w emulsion and its application to transcatheter arterial embolization therapy. Adv Drug Deliv Rev 45:27-45

Jimenez-Colmenero F (2013) Potential applications of multiple emulsions in the development of healthy and functional food. Food Res Int 52:64-74. https://doi.org/10.1016/j.foodres.2013.02.040

Matos M, Gutierrez G, Coca J, Pazos C (2014) Preparation of water-inoil-in-water $\left(\mathrm{W}_{1} / \mathrm{O} / \mathrm{W}_{2}\right)$ double emulsions containing trans-resveratrol. Colloids Surfaces A Physicochem Eng Aspects 442:69-79. https://doi.org/10.1016/j.colsurfa.2013.05.065

Mehrania MA, Jafari SM, Makhmal-Zadeh BS, Maghsoudlou Y (2017) Rheological and release properties of double nano-emulsions containing crocin prepared with Angum gum, Arabic gum and whey protein. Food Hydrocoll 66:259-267. https://doi.org/10.1016/j. foodhyd.2016.11.033

Mohammadi A, Jafari SM, Esfanjani AF, Akhavan S (2016) Application of nano-encapsulated olive leaf extract in controlling the oxidative stability of soybean oil. Food Chem 190:513-519. https ://doi.org/10.1016/j.foodchem.2015.05.115

Molski M (2009) Beauty chemistry. WN PWN SA, Warszawa (in Polish)

Okochi H, Nakano M (2000) Preparation and evaluation of W/O/W type emulsions containing vancomycin. Adv Drug Deliv Rev 45:5-26

Pal R (1996) Multiple O/W/O emulsion rheology. Langmuir 12(9):2220-2225. https://doi.org/10.1021/la950475h

Perez-Moral N, Watt S, Wilde P (2014) Comparative study of the stability of multiple emulsions containing a gelled or aqueous internal phase. Food Hydrocoll 42:215-222. https://doi.org/10.1016/j. foodhyd.2014.05.023

Sajjadi S, Jahanzad F, Yianneskis M, Brooks DW (2003) Phase inversion in abnormal $\mathrm{O} / \mathrm{W} / \mathrm{O}$ emulsions. 2. Effect of surfactant hydrophilic-lipophilic balance. Ind Eng Chem Res 42:3571-3577. https ://doi.org/10.1021/ie021044e

Schuch A, Deiters P, Henne J, Kohler K, Schuchmann HP (2013) Production of W/O/W (water-in-oil-in-water) multiple emulsions: droplet breakup and release of water. J Colloid Interface Sci 402:157-164. https://doi.org/10.1016/j.jcis2013.03.066

Schuch A, Wernger J, Schuchmann HP (2014) Production of W/O/W doble emulsions. Part II: Influence of emulsification device on release of water by coalescence. Coloids Surfaces A Physicochem Eng Aspects 461:344-351. https://doi.org/10.1016/j.colsu rfa.2013.11.044

Ursica L, Tita D, Palici I, Tita B, Vlaia V (2005) Particle size analysis of some water/oil/water multiple emulsions. J Pharm Anal 37:931-936. https://doi.org/10.1016/j.jpba.2004.10.055

Yamanaka Y, Kobayashi I, Neves MA, Ichikawa S, Uemura K, Nakajima M (2017) Formulation of W/O/W emulsions loaded with short-chain fatty acid and their stability improvement by layerby-layer deposition using dietary fibers. LWT Food Sci Technol 76:344-350. https://doi.org/10.1016/j.1wt.2016.07.063

Publisher's Note Springer Nature remains neutral with regard to jurisdictional claims in published maps and institutional affiliations. 